\title{
Preservação do patrimônio histórico das antigas vinícolas da região sul de Santa Catarina
}

\section{Preserving the heritage of old wineries of the southern region of Santa Catarina}

\author{
Fernando Barth ${ }^{1}$ \\ fernando.barth@ufsc.br \\ Tatiana Amaral ${ }^{2}$ \\ tat.arq@brturbo.com.br
}

\section{Resumo}

Este artigo busca avaliar a evolução e o estado de conservação de duas antigas vinícolas da região de Urussanga (SC), em função da relevância histórica, arquitetônica e turística que representam para essa região. Primeiramente, será realizado um breve histórico dessas vinícolas e a fundamentação do patrimônio industrial e arquitetônico. Posteriormente, é realizada a análise das características arquitetônicas e construtivas e do estado atual de conservação das edificações. A sistematização dos resultados pode contribuir para incrementar o conhecimento sobre essas antigas vinícolas, ressaltar a necessidade de melhorias e intervenções nessas edificações e, por fim, promover a valorização do patrimônio arquitetônico e cultural. Essas vinícolas representam uma parte significativa da história da imigração italiana, de modo a manter o elo com aqueles que plantaram suas raízes e sua cultura na região. Roteiros turísticos qualificados, que incluam as vinícolas e suas paisagens, podem reforçar a identidade cultural, atraindo pessoas e recursos para garantir a preservação do patrimônio histórico das antigas vinícolas do sul de Santa Catarina.

Palavras-chave: Vinícola; Patrimônio; Arquitetura; Cultura; Preservação.

\begin{abstract}
This work aims to assess the evolution and the conservation status of two ancient wineries in Urussanga (SC) region, due to its historical, architectural and touristic significance. First, there will be a brief historic of these wineries and the bases of industrial and architectural heritage. Later, it is performed the analysis of the architectural and construction characteristics and the current condition of the buildings. The systematization of the results may contribute to increase knowledge about these ancient wineries, emphasizing the need for improvement and interventions in these buildings and, finally, promote the appreciation of the architectural and cultural heritage. These wineries represent a relevant part of the history of Italian immigration in order to maintain the link with those who planted their roots and their culture in the region. Qualified tourist itineraries that include the wineries and their landscapes, can strengthen cultural identity, attracting people and resources to ensure the preservation of historical heritage of southern Santa Catarina's wineries.
\end{abstract}

Keywords: Winery; Heritage; Architecture; Culture; Preservation.

1 Professor titular do Departamento de Arquitetura e Urbanismo da Universidade Federal de Santa Catarina (UFSC).

2 Mestre em Arquitetura e Urbanismo pela UFSC. 


\section{A preservação do patrimônio histórico, arquitetônico e cultural}

A preservação de edifícios históricos e culturais passa por um processo de conscientização nos diversos segmentos da sociedade, tendo como resultado intervenções do Estado e de organizações não governamentais que procuram responder a essas preocupações, buscando, deste modo, reforçar a identidade sociocultural das comunidades. Contudo, as edificações e as áreas industriais nem sempre são reconhecidas como algo a ser valorizado e preservado. A perda dos interesses comerciais, a falta de critérios específicos para sua conservação e a especulação imobiliária fazem com que esses imóveis estejam suscetíveis à ociosidade, degradação e demolição. As atividades industriais geraram, ao longo do tempo, elementos que hoje fazem parte do nosso patrimônio cultural. Esses elementos são representados pelos edifícios industriais, infraestruturas e equipamentos, além de máquinas e utensílios que passaram a fazer parte da memória e da identidade das sociedades. O estudo e a recuperação desses testemunhos são fundamentais na compreensão e documentação de um período essencial na história das nossas cidades. Segundo Fontana (2005), os vestígios da industrialização constituem objetos de pesquisa da arqueologia industrial que, como método de estudo, identifica, analisa e cataloga bens e processos industriais, a fim de aprofundar o conhecimento, incentivar a salvaguarda e o restauro, podendo, ainda, adequar edifícios históricos industriais a novos usos. Observa-se que o patrimônio industrial pode ser material ou imaterial, não se limitando ao edificado ou maquinários, podendo também abranger o conhecimento das técnicas, do saber fazer e das relações históricas e sociais que se desenvolvem em torno do patrimônio.

\section{A imigração italiana na região sul de Santa Catarina}

A história vinícola do Brasil começa com a sua colonização, quando Martin Afonso de Souza planta as primeiras mudas de uvas na Capitania de São Vicente, no século XVI. Na região sul do Brasil, a viticultura foi introduzida pelos jesuítas no século XVII, durante o processo de implantação das Missões Jesuíticas. No entanto, o grande desenvolvimento do setor vinícola acontece no final do século XIX, com a chegada dos imigrantes italianos no país. Segundo Souza (2011), em 1875 teve início um grande fluxo imigratório com assentamentos desde o Espírito Santo até o Rio Grande do Sul, com o intuito de substituir a mão de obra escrava nos cafezais, suprir trabalho nas minas de carvão, além de colonizar terras nos estados do sul. Os imigrantes italianos que chegaram ao estado de Santa Catarina provinham, em sua grande maioria, do norte da Itália. Entretanto, os primeiros imigrantes italianos que chegaram ao estado em 1836 eram oriundos da Sardenha, fundando a colônia de Nova Itália, atual São João Batista (SC). Esses imigrantes pioneiros chegaram em número reduzido e pouco influenciaram na demografia do estado. A partir de 1875, o estado recebeu um número maior de imigrantes italianos, dando origem às colônias de Rio dos Cedros, Rodeio, Ascurra e Apiúna, próximas à colônia alemã de Blumenau. Nesse mesmo período, imigrantes provenientes da Lombardia e do Trentino fundaram Nova Trento e Porto Franco, atual Botuverá (SC). Nos anos seguintes, a região do sul de Santa Catarina passou a ser o principal foco de colonização italiana, dando origem às colônias de Azambuja, Urussanga e Criciúma. Esses imigrantes provinham principalmente do Vêneto e, em menor número, da Lombardia e de Friuli-Veneza Júlia, dedicando-se principalmente à mineração do carvão e ao desenvolvimento da agricultura, com destaque para o cultivo de uvas e a produção artesanal de vinhos. Com o tempo, esses imigrantes fundaram várias vinícolas, elevando a qualidade do vinho e impulsionando a economia local. As primeiras adegas da região foram instaladas no final do século XIX, funcionando na parte inferior das residências, que em quase sua totalidade eram construídas em pedra e semienterradas.

O desenvolvimento das vinícolas no sul de Santa Catarina, iniciado com as mudas trazidas da Itália, deu origem aos primeiros parreirais e à produção artesanal de vinho no final do século XIX. A atividade vitivinícola nessa região continua ainda hoje, sendo que a cidade de Urussanga e a localidade de Azambuja, na cidade de Pedras Grandes, são territórios de destaque no cultivo de vinhas, em especial da uva Goethe. Maestrelli (2011) relata que as primeiras videiras plantadas nas localidades de Rio Carvão e Rancho dos Bugres eram utilizadas para produzir o vinho e o vinagre de uva para consumo doméstico. A adaptação das videiras europeias não foi uma atividade fácil, uma vez que as condições climáticas da região eram diversas do país 
de origem das mudas. Contudo, novos tipos de uvas foram implantados na região, sobretudo americanas ou híbridas, que apresentavam maior produtividade.

No início do século XX, chegou à Urussanga o advogado e representante do Consulado Italiano, Giuseppe Caruso Mac Donald, que trouxe para Urussanga as primeiras mudas da uva Goethe. Rebollar e Velloso (2007) relatam que essa uva, desenvolvida no século XIX nos Estados Unidos por Robert Staniford Rogers, é um híbrido de variedades que apresenta alta resistência fitossanitária. Esse tipo de uva, considerada seminobre, era composta por $87,5 \%$ de cepas europeias da familia dos moscatéis e 12,5\% de cepas americanas. A uva Goethe teve uma ótima adaptação aos solos da região e às condições climáticas locais. Esse tipo de muda foi distribuído aos imigrantes e, por sua boa aceitação, foi amplamente cultivado em toda a região, inclusive em áreas centrais de Urussanga. Aos poucos, essa atividade foi se tornando comercial, deixando as pequenas cantinas para a produção em larga escala. Segundo Maestrelli (2011), a uva Goethe passou por um processo de mutação natural, produzindo vinho com uma sutil diferença, porém muito apreciada na região. A mutação da uva Goethe ocorreu somente em Urussanga, vindo a se chamar Goethe Primo, cultivada até os dias atuais. O descobrimento das jazidas de carvão e a construção da estrada de ferro na região facilitou o transporte da bebida para outros locais, extrapolando os limites do estado catarinense. Segundo Costa (2000), os vinhos eram comercializados nos estados do Paraná, Rio de Janeiro, São Paulo e em alguns estados da região norte e nordeste do Brasil, e apenas nos primeiros dez anos de funcionamento da ferrovia, saíram cerca de 85 mil litros de vinho de Urussanga.

No auge da comercialização, alguns vinhos da região foram colocados à venda em pontos importantes como o Copacabana Palace, o Jockey Club Brasileiro e as reuniões políticas no Palácio do Catete, na época em que o Rio de Janeiro era a capital do país. Nos anos 1950, o município de Urussanga era intitulado "Terra do Bom Vinho e da Cultura Italiana" e, em 2004, ganhou o título de "Capital Catarinense do Bom Vinho" pela Assembleia Legislativa do Estado de Santa Catarina. A região ficou conhecida pela produção de vinhos e pelos títulos e prêmios nacionais e internacionais conquistados ao longo dos anos. Devido a isso, o governo de Getúlio Vargas, por intermédio do Ministério da Agricultura, decidiu apoiar a vitivinicultura na região. Assim, no ano de 1942 foi implantada a Subestação de Enologia na cidade de Urussanga, que visava à realização de pesquisas com variedades de uvas e à busca de maior qualidade.

\section{O Vale da Uva Goethe e os vinhos com indicação de procedência}

$\mathrm{Na}$ atualidade, a Estação Experimental da Empresa de Pesquisa Agropecuária e Extensão Rural de Santa Catarina (Epagri) continua a apoiar as pesquisas de vitivinicultura em Urussanga, pois o setor vinícola da região passou por uma crise a partir dos anos 1940, que coincidiu com a exploração das minas de carvão. Com o tempo, muitos agricultores deixaram as atividades agrícolas e passaram a trabalhar nas minas, buscando aumentar o rendimento mensal e garantir a aposentadoria. Apesar da mudança do perfil da população do município, a produção do vinho com a uva Goethe se mantém até os dias atuais. Em 2005, produtores de vinho dessa uva formaram uma associação denominada ProGoethe, com o apoio do Sebrae, do governo do estado, da Universidade Federal de Santa Catarina e da Epagri. O principal objetivo dessa associação foi a busca pelo reconhecimento da qualidade e da tipicidade dos vinhos produzidos pela uva Goethe na região de Urussanga por meio da Indicação Geográfica. Em Santa Catarina, a primeira Indicação Geográfica foi atribuída aos Vales da Uva Goethe pelo Instituto Nacional da Propriedade Industrial, do Ministério do Desenvolvimento,

Figura 1 - Região produtora da Uva e do Vinho Goethe.
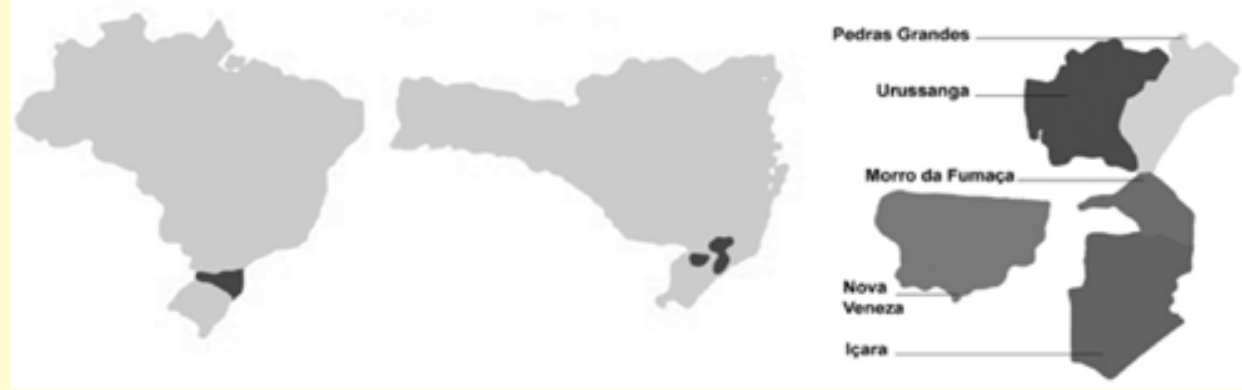
Indústria e Comércio Exterior. Em 2011, foi deferida a Indicação de Procedência dos vinhos tranquilos, espumantes e frisantes dos vales da Uva Goethe. A primeira indicação geográfica do estado abrange os municípios de imigração italiana de Pedras Grandes e de Urussanga, mostrados na Figura 1. 


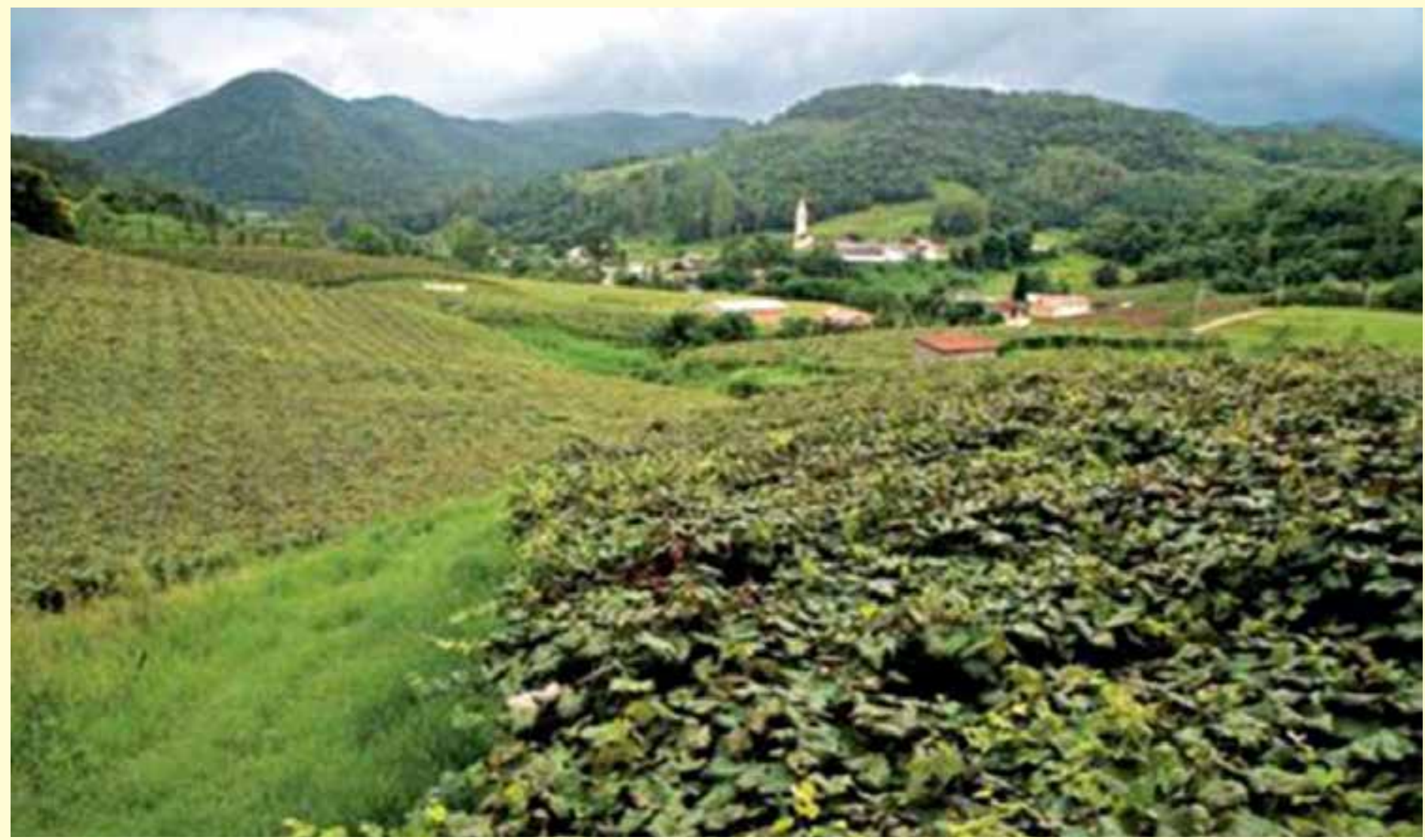

Fonte: Ronald Sharp (2012).

A uva Goethe é muito sensível a chuvas na época de colheita, sendo difícil de vinificar nestas condições. Entretanto, segundo Vieira et al. (2014), se adaptou bem às condições locais, produzindo um vinho branco típico, decorrentes das condições do clima e do solo. O produto dessa uva adquiriu, com o tempo, identidade própria, deixando como legado não só o produto final vinho, mas também a paisagem cultural vitícola, que pode ser observada na Imagem 1. A qualidade e a tipicidade dos vinhos, os parreirais e a arquitetura ítalo-brasileira das vinícolas localizadas nos Vales da Uva Goethe (Figura 1) geraram na região uma forte identidade cultural.

As primeiras vinícolas, fundadas na região estão localizadas no centro histórico de Urussanga, sinalizadas em vermelho na Imagem 2. Algumas delas continuam a fazer parte do conjunto arquitetônico ítalo-brasileiro, sendo que outras já foram parcial ou totalmente demolidas. Encontra-se também na zona rural da região algumas

Imagem 2 - Localização das vinícolas na área urbana do Município de Urussanga

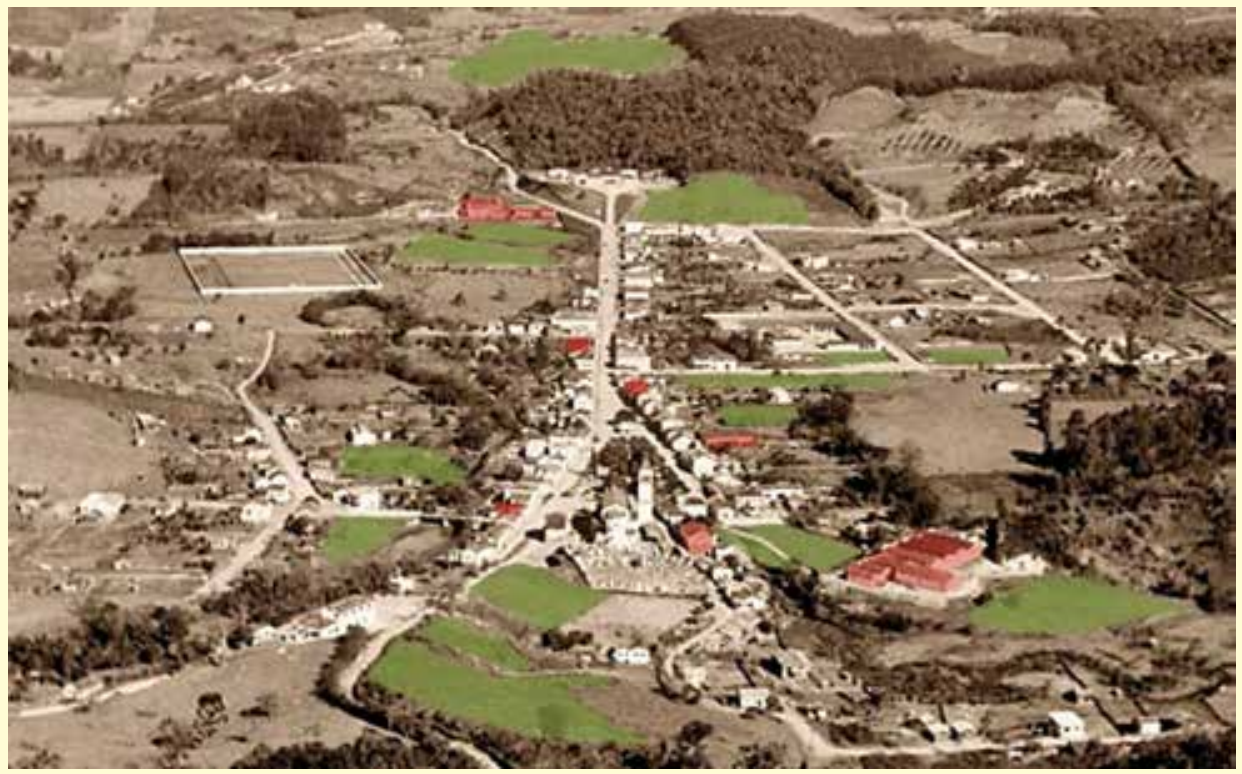

Fonte: Amaral (2014, p. 41). vinícolas antigas, assim como muitos produtores de vinhos artesanais. A Vinícola Caruso Mac Donald foi a primeira fábrica a produzir vinhos na região, localizada na cidade de Urussanga.

Surgiram depois outras indústrias vinícolas na cidade que produziam vinhos de várias cepas, entre elas a Goethe, das quais vale destacar a Vinícola Cadorin; Vinhos De Bona, da família Vincenzo de Bona; a Vinícola Bez Batti, que produzia o vinho Santé, pela família de Vincenzo de Bona e, posteriormente, pela família de Vittorio Bez Batti; a Vinícola 
Lacrima Christi, da família Pietro Damian; a Vinícola Barzan, da família Ignazio Barzan; e a Vinícola Ferraro \& Batista, da família Sílvio Ferraro. Na localidade vizinha de Azambuja, em Pedras Grandes (SC), localiza-se a Vinícola Silvestre \& Fornasa, da família Abramo Silvestre.

$\mathrm{Na}$ Figura 2, podem-se observar as atuais vinícolas produtoras de vinho com as uvas dos Vales da Uva Goethe. Dentre as vinícolas históricas da região, destacam-se duas edificações construídas na primeira metade do século XX, localizadas no centro histórico de Urussanga: Vinícola Caruso Mac Donald e Vinícola Cadorin. Neste trabalho, serão descritas brevemente as características arquitetônicas, assim como os materiais e as técnicas construtivas, de modo a avaliar o estado de conservação atual das vinícolas e as condições do seu entorno.

Figura 2 - Vinícolas produtoras do Vale da Uva Goethe.
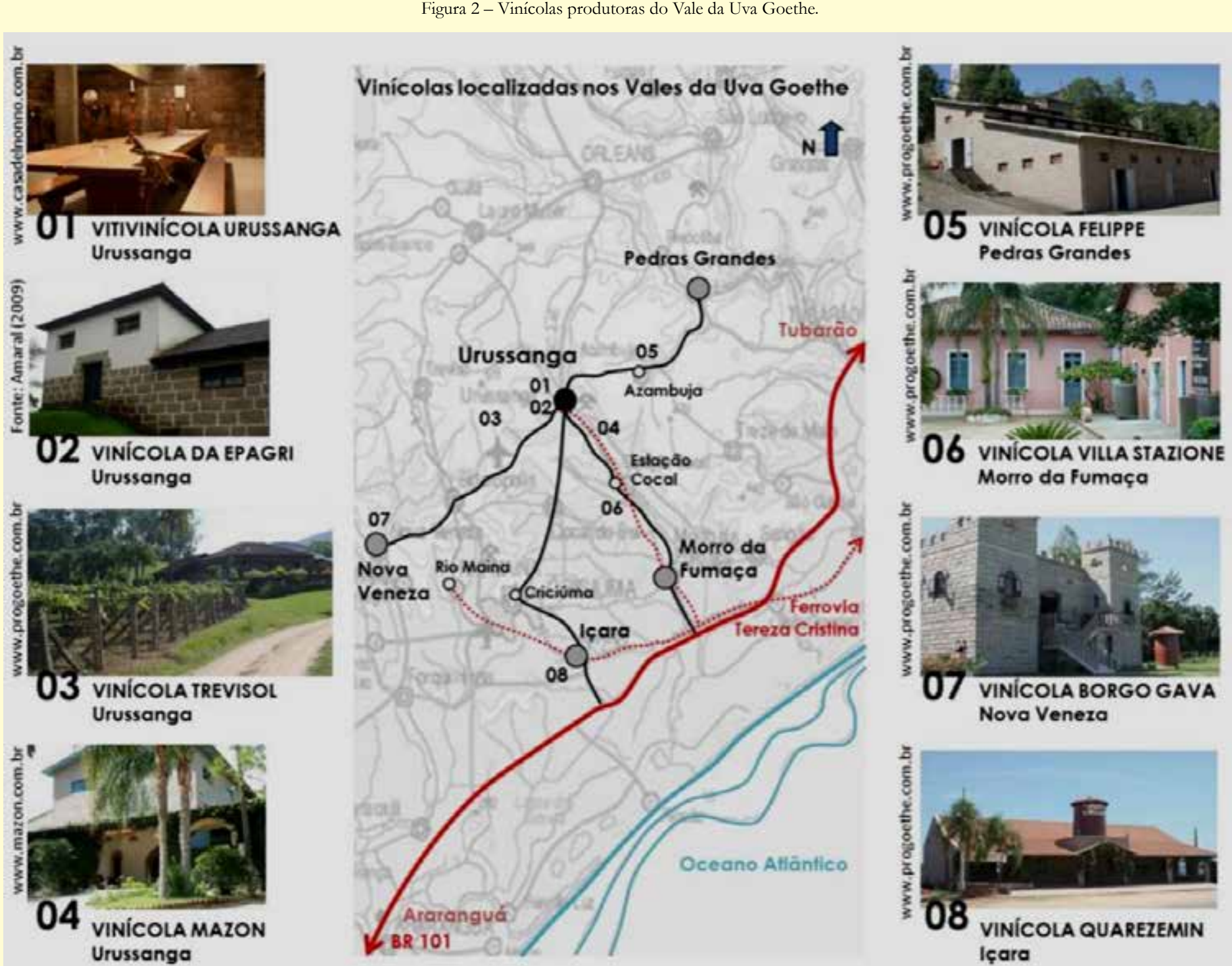

Fonte: Amaral (2014, p. 43).

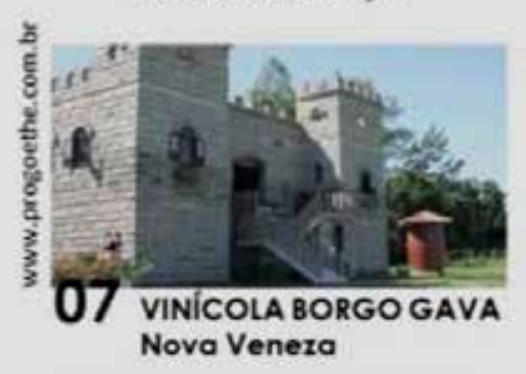

Essas vinícolas representam parte da história da industrialização no município que, com as minas de carvão e a Ferrovia Tereza Cristina, mantiveram por longo tempo as atividades econômicas da região. $\mathrm{Na}$ época da colonização, era comum o plantio de uvas e a produção artesanal de vinho junto às residências urbanas. No início do século XX, a produção de vinho deixa de ser artesanal, tomando contornos mais profissionais. Mais precisamente em 1913, inicia-se a produção vitivinícola em escala industrial pela Vinícola Caruso Mac Donald, precursora de uma série de vinícolas que viriam a surgir na área central de Urussanga.

Geralmente as vinícolas eram construídas anexas ou próximas das residências dos produtores, em área urbana, onde as bebidas poderiam ser comercializadas junto aos armazéns e comércios locais. Acredita-se que o crescimento dessas indústrias aconteceu pelas vantagens da implantação em área urbana e pela facilidade de escoamento da bebida para outros locais do país, tendo em vista que a estação da Estrada de Ferro Tereza Cristina era localizada na área central, muito próxima às vinícolas. Inicialmente, as vinícolas 
cultivavam seus próprios vinhedos e também adquiriam a sua matéria prima dos produtores rurais e do entorno da área central. Deste modo, a paisagem local era caracterizada por grandes vinhedos, inclusive na área urbana central, sinalizados na Imagem 2.

Simultaneamente ao fortalecimento da indústria vitivinícola, surge a atividade mineradora em Urussanga, dando origem a alguns núcleos de ocupação operária próxima às áreas de mineração, o que alterou sensivelmente a configuração rural dessas localidades. De acordo com Belolli et al (2002), à medida que essa atividade ia se desenvolvendo, surgiam novos setores empresariais que impulsionaram o crescimento demográfico de Urussanga e de toda a região sul catarinense. $\mathrm{O}$ desenvolvimento econômico gerado pela atividade mineradora na região teve um efeito paradoxal sobre a indústria do vinho. Essa atividade possivelmente incentivou ainda mais a produção da bebida na localidade e consolidou o processo industrializado de sua fabricação. Por outro lado, competia pela mão de obra do agricultor rural, ao oferecer-lhe trabalho nas minas. Acredita-se que as vinícolas, apesar de não terem criado fortes vetores de crescimento urbano, reforçaram o comércio local e foram elementos fundamentais no desenvolvimento econômico da região.

\section{O patrimônio arquitetônico e cultural das vinícolas de Urussanga}

O patrimônio histórico pode ser definido como um bem material, natural ou imóvel que possui significado e importância artística, cultural, religiosa, documental ou estética para a sociedade. Neste contexto, o patrimônio arquitetônico das antigas vinícolas de Urussanga se insere no conjunto de bens construídos e produzidos pelas sociedades passadas, que necessitam de pesquisa e preservação cultural. O Art. 216, Capitulo 3, Seção II da Constituição Federal de 1988, constitui e assegura uma proteção específica ao patrimônio cultural, passando a abranger não só os bens de natureza material como também os imateriais, tais como formas de expressão; modos de criar, fazer e viver; criações científicas, artísticas e tecnológicas; obras, objetos, documentos, edificações e demais espaços destinados às manifestações artístico-culturais; além de conjuntos urbanos e sítios de valor histórico, paisagístico, artístico, arqueológico, paleontológico, ecológico e científico. Segundo Dantas (2006), os bens imateriais, de modo similar aos bens materiais que são protegidos pela política do tombamento, têm seu valor inscrito na dinâmica dos processos culturais e das práticas sociais. Desse modo, o patrimônio dessas vinícolas também constitui um patrimônio imaterial por estar conceituado e ter fortes vínculos com práticas, representações, expressões, conhecimentos e técnicas da vitivinicultura. Abrange os instrumentos, objetos, artefatos e lugares associados ao cultivo de uvas, produção de vinhos, aspectos coletivos e comunidades que se reconhecem como parte integrante desse patrimônio cultural que, transmitido de geração em geração, apresenta a capacidade de recriar-se nas comunidades e de interagir com a história e com o ambiente, mostrando-se capaz de gerar sentimentos de identidade local, de preservação e de continuidade da cultura da região.

As gerações que sucederam os primeiro imigrantes italianos da região ampliaram as vinícolas, sendo que algumas delas se mantêm em funcionamento até os dias atuais. Entre elas estão a Vinícola Caruso Mac Donald e a Vinícola Cadorin, esta última tombada pela Fundação Catarinense de Cultura em 2001. A primeira vinícola, fundada por Giuseppe Caruso Mac Donald, trouxe para a cidade, além das primeiras mudas da uva Goethe, o interesse pela produção do vinho de qualidade. Segundo Costa (2000), Giuseppe chegou a Urussanga como regente do consulado italiano e tinha como papel acompanhar e orientar as colônias de imigrantes italianos em Santa Catarina. No final do século XIX, se estabeleceu na cidade e começou o plantio de videiras, distribuindo a outros imigrantes da região diversas mudas de uvas, entre elas a Goethe. Giuseppe possuía uma admirável biblioteca vitivinícola, com livros e revistas que auxiliaram na época a fabricação de vinhos para consumo próprio e que também contribuíram para a sua difusão entre outras famílias de vitivinicultores. Mais tarde, Giuseppe fundou um jornal chamado La Pátria, que entre outras coisas, dava instruções em italiano sobre como cultivar videiras na região. A empresa Caruso Mac Donald, fundada em 1913, foi a primeira vinícola a atuar em nível industrial no sul do estado de Santa Catarina. No seu auge, a empresa chegou a ter capacidade de estocagem de dois milhões de litros, usados para engarrafamento de vinhos e vermutes, mas a produção de vinhos foi interrompida em 1998. A vinícola passou por algumas transformações ao longo dos anos, em função do aumento e posterior diminuição da produção e das vendas. 


\section{Método da pesquisa, resultados e discussões}

A abordagem qualitativa e quantitativa da pesquisa abrangeu a seleção de estudos de caso representativos e de valor histórico das antigas vinícolas de Urussanga. A pesquisa bibliográfica buscou documentos em jornais, revistas e periódicos que tratassem das vinícolas no Brasil e, mais especificamente, na região de Urussanga. A pesquisa documental, realizada na Fundação Catarinense de Cultura e na Prefeitura de Urussanga, buscou levantar fotografias antigas, mapas e documentos históricos. Nos acervos das duas vinícolas selecionadas obtiveram-se outros textos, cartas, documentos de empresa e registros dos antigos e novos proprietários. Além disso, durante a pesquisa de campo foram realizadas observações sistematizadas in loco, levantamento gráfico e fotográfico das edificações, assim como entrevistas informais com atuais proprietários e antigos trabalhadores das vinícolas. Deste modo, foi possível conhecer grande parte da história dessas edificações, dos seus moradores e dos métodos de trabalho. Também se buscou determinar a cronologia histórico-construtiva dessas edificações, por meio do estudo das características arquitetônicas, dos materiais e das técnicas construtivas empregadas e da análise do estado atual dos edifícios. Utilizaram-se algumas ferramentas de análise propostas pela Arqueologia da Arquitetura, que permitiram identificar as modificações realizadas nas vinícolas, estabelecendo uma cronologia relativa a partir de fatores tecnológicos, formais e funcionais. As etapas de construção e ampliações dessas vinícolas serão objeto de outra publicação, por apresentarem uma grande quantidade de análises, graficações e resultados.

As análises preliminares permitiram identificar as diversas fases evolutivas, apresentadas por Amaral e Barth (2014), correspondentes a ampliações e construções de edifícios anexos às antigas vinícolas. Atualmente, apenas uma parte da vinícola Caruso Mac Donald, a mais antiga da região, está sendo utilizada para a produção de destilados e de vermute. Grande parte das suas salas encontra-se sem cobertura, expondo paredes e equipamentos às intempéries. Nesses ambientes, encontram-se os antigos recipientes em que eram elaborados e conservados os vinhos, atualmente em estado crítico de conservação. O primeiro edifício construído abrigava os ambientes de produção, onde foram instalados os primeiros tonéis utilizados na fabricação do vinho. Com o aumento das vendas, novas salas foram construídas ao longo do tempo para suprir as necessidades da produção, formando um conjunto de edifícios térreos, como pode ser visto nas Imagens 3 e 4.

Imagem 3 - Vista da Vinícola Caruso MacDonald.

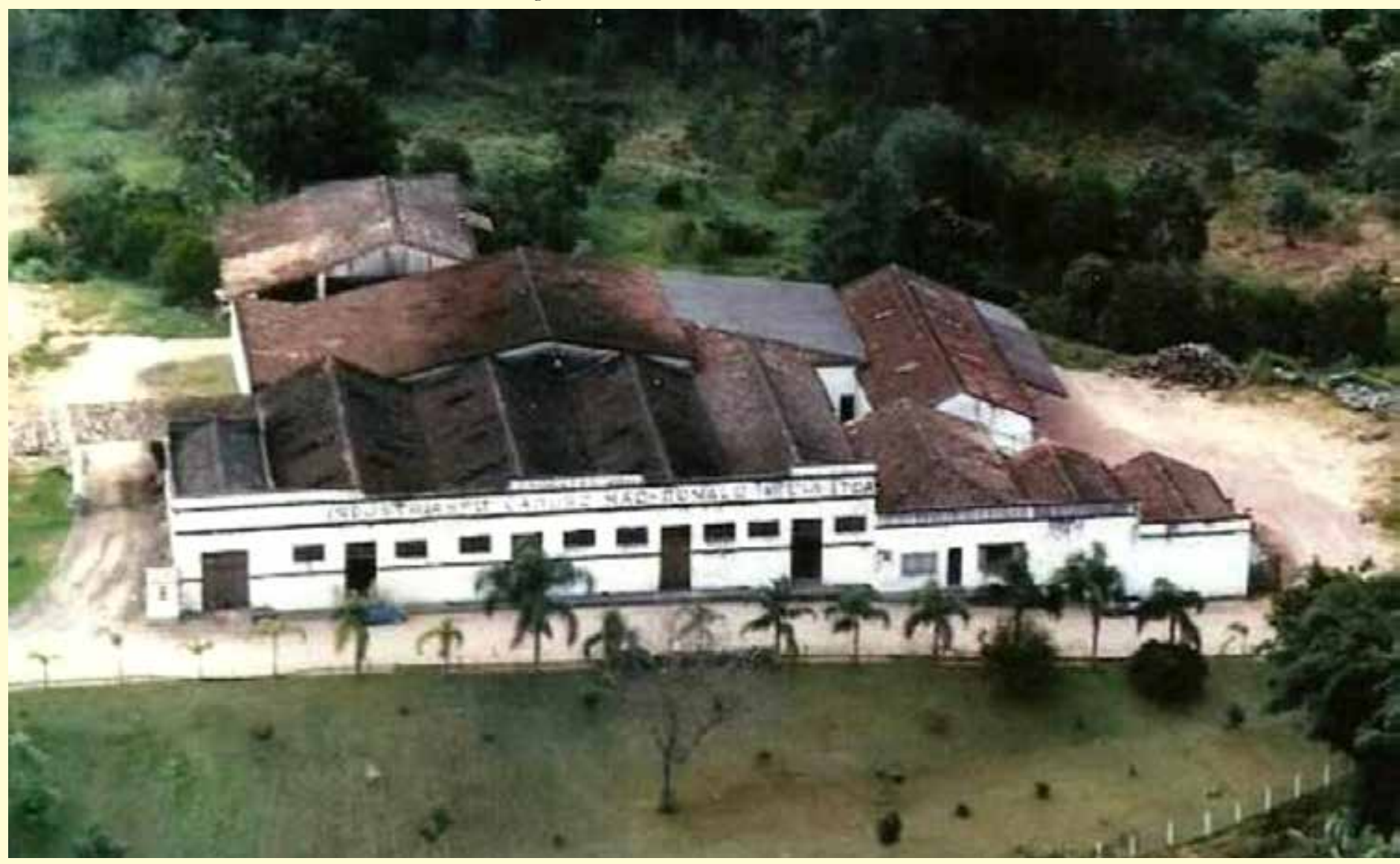

Fonte: Amaral (2014, p. 72). 


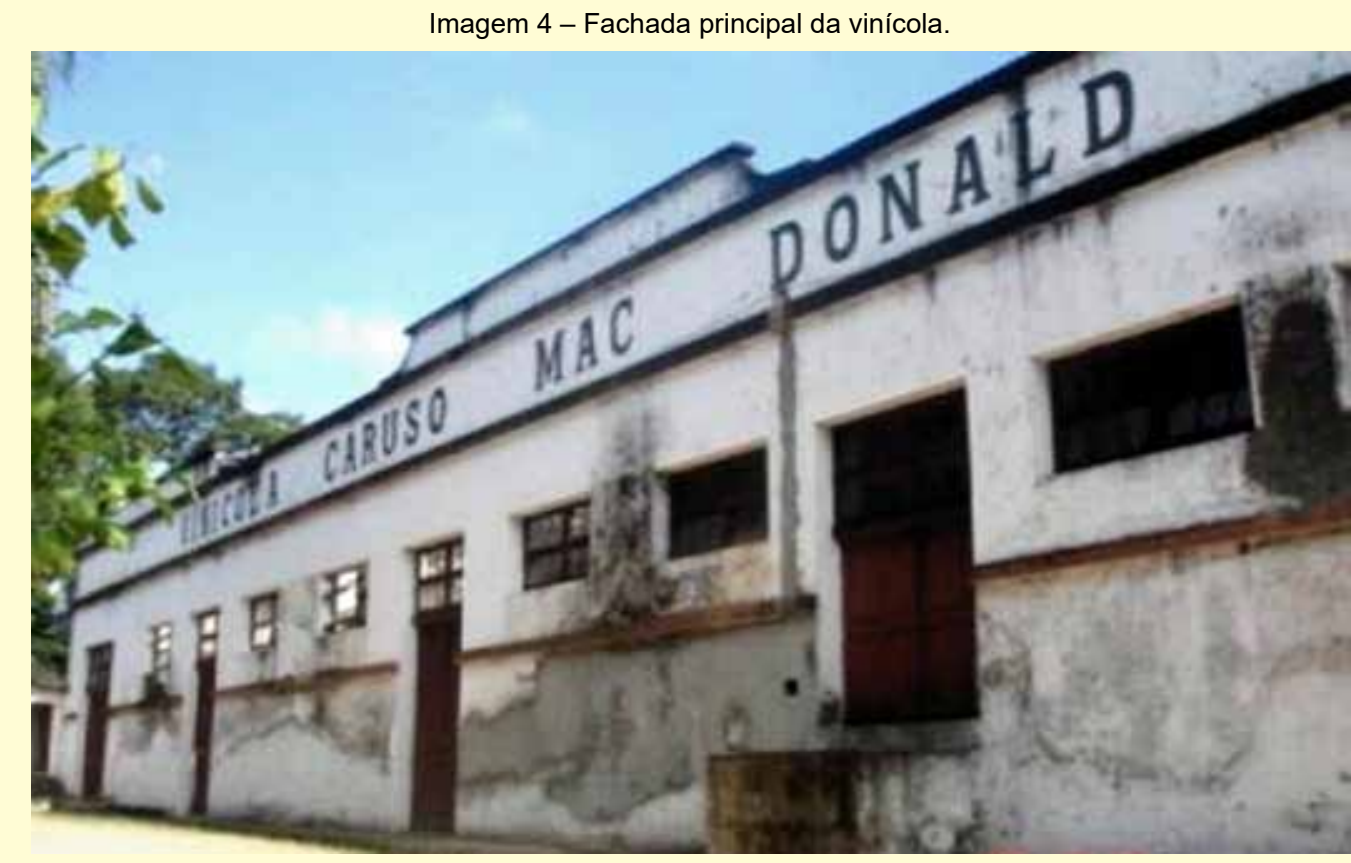

Fonte: Amaral (2014, p. 72).
O avançado estado de deterioração das fachadas e das esquadrias do edifício pode ser relacionado à inexistência ou falta de manutenção da cobertura em algumas de suas partes. A ausência de manutenção propiciou infiltrações e goteiras originadas por telhas quebradas ou deslocadas, ocasionando umidade e condições propícias para a proliferação de agentes biológicos nas paredes e esquadrias. Devido ao processo acelerado de degradação, algumas coberturas desabaram e outras foram aos

poucos sendo removidas por questões de segurança. A situação atual das coberturas provocou a desativação de ambientes em que se produziam o vinho, sendo que os antigos tonéis de armazenamento encontram-se atualmente expostos às intempéries.

Outro empreendimento que se destacou na história do município de Urussanga foi a Vinícola Cadorin, fundada em 1919 pelo imigrante Lorenzo Cadorin. Descendente de uma família de ferreiros italianos, ele aliou essa profissão com a de produtor de vinhos, iniciando com uma pequena produção de vinho branco em sua própria residência, na localidade de Rio Salto, zona rural de Urussanga. Em 1914, Lorenzo se mudou para o centro da cidade, na Praça Anita Garibaldi, continuando com o trabalho de ferreiro e com a pequena venda artesanal de vinhos. Alguns anos depois, com o intuito de aumentar a produção, adquiriu um terreno na atual Rua Américo Cadorin e começou a construção da vinícola. Conforme relata Orlando Cadorin, filho de Lorenzo, a edificação foi construída em etapas com a ajuda de seu pai e por pedreiros contratados. Segundo Matiola et al (2010), a primeira safra de vinho produzida no local aconteceu em 1921.

No ano de 1927, quando a residência da família foi construída anexa à fábrica, a capacidade de produção e estocagem já havia aumentado. Segundo relato de Orlando Cadorin em 1930 a capacidade de estocagem era de 38 mil litros, sendo que, em 1934, aumentou para 50 mil litros, passando a fabricar também outras bebidas como vermute, bitter e conhaque. As fachadas principais da vinícola podem ser vistas na imagem 5. Assim como outras vinícolas da região de Urussanga, a Cadorin também comercializava suas bebidas em diversas capitais do país. A vinícola funcionou sob a supervisão de Lorenzo até o ano de 1951. A partir de 1952, a fábrica passou a ser administrada pelos irmãos Américo e Orlando, com a denominação de Vinícola Irmãos Cadorin. Américo deixou a sociedade em 1962, quando novos sócios foram admitidos, Airton Araújo e João Bendo. De 1967 a 1992, ano de encerramento de suas atividades, a Vinícola Cadorin passou por várias administrações. Posteriormente ela funcionou como Museu do Vinho e, conforme descreve

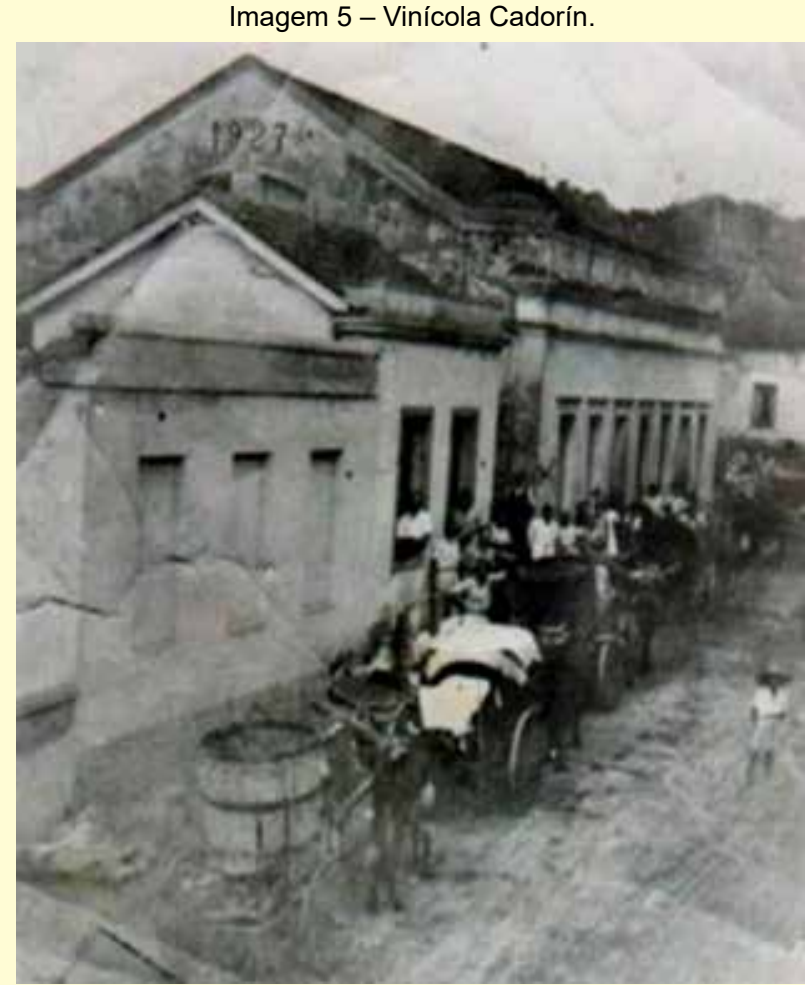

Fonte: Amaral (2014, p. 97). 
Imagem 6 - Vinícola Cadorín com rua calçada.

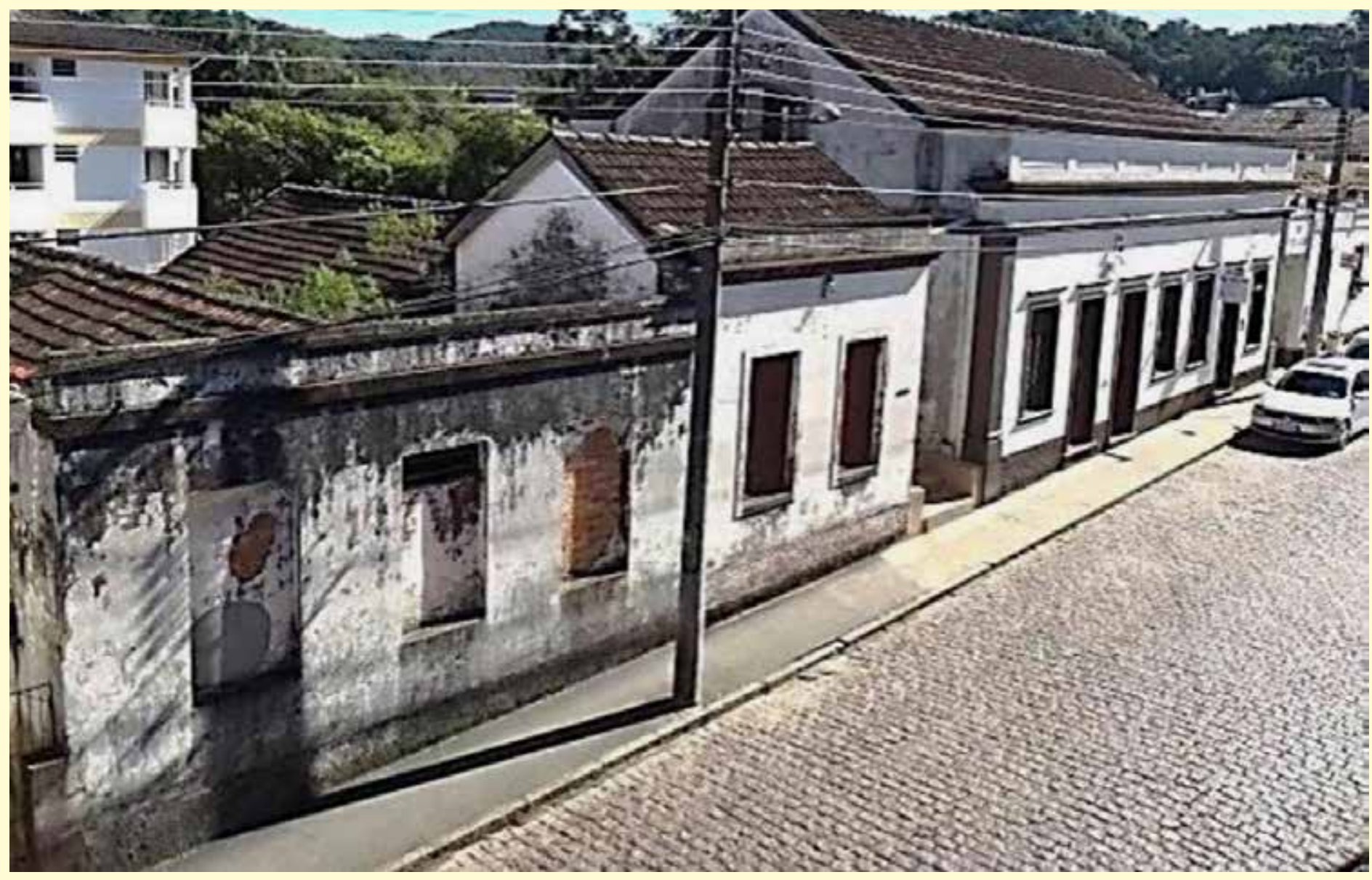

Fonte: Amaral (2014, p. 97).

Matiola (2010), recebeu visitantes de várias partes do país e mesmo estrangeiros que vinham especialmente para conhecer um pouco da história e da bebida tradicional da região. Depois do falecimento de Orlando Cadorin, em 2012, a vinícola foi fechada para visitação. Atualmente, o estado de conservação dos antigos ambientes de produção é crítico, sobretudo das estruturas de cobertura, impossibilitando que esse espaço fique aberto à visitação pública. Um dos ambientes do complexo da vinícola abriga algumas ferramentas utilizadas na antiga ferraria, conforme mostra a Imagem 7. A vinícola foi tombada pela Fundação Catarinense de Cultura, pela Lei de Tombamento Estadual, homoloImagem 7 - Ferraria da Vinícola Cadorin.

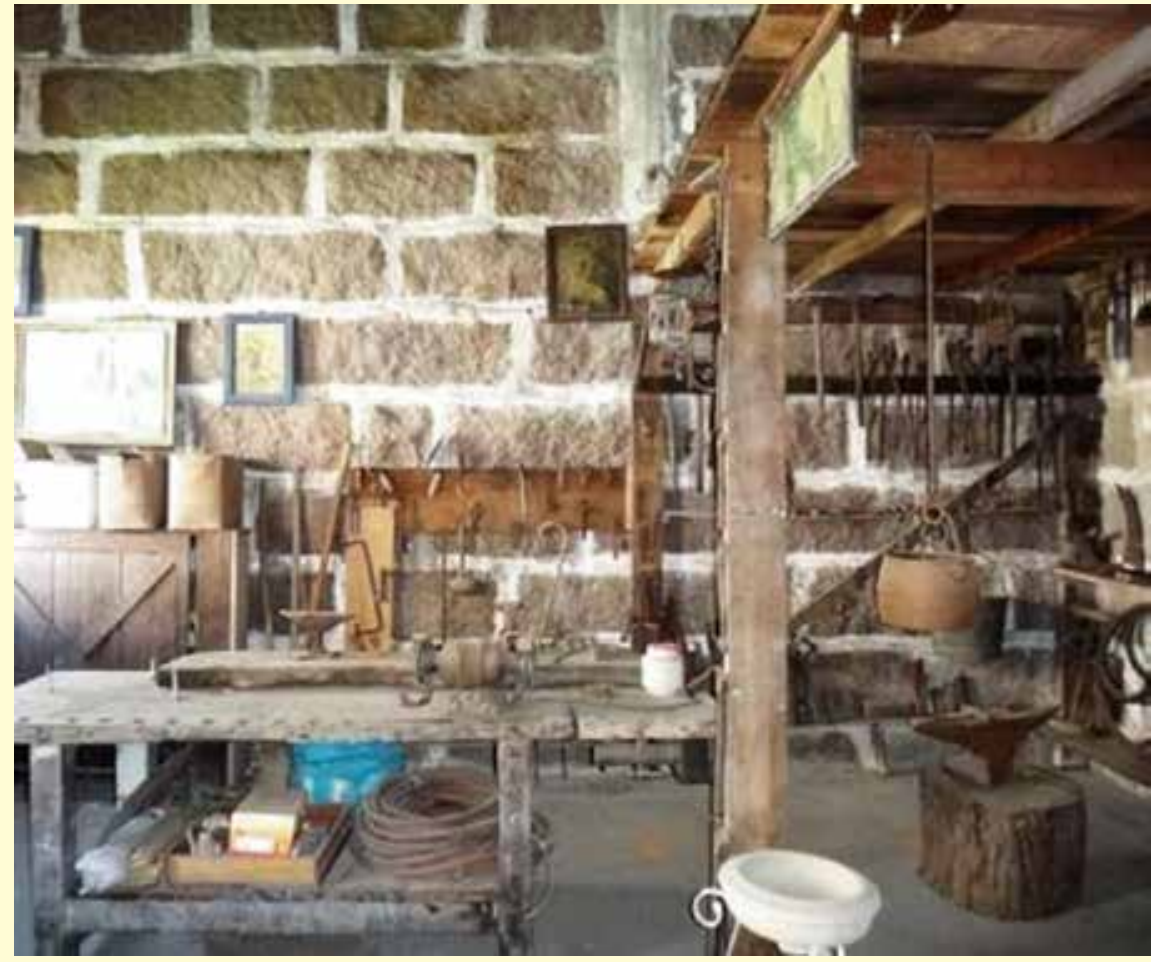

Fonte: Amaral (2014, p. 78) gada pelo Decreto n ${ }^{\circ} 3.463$, de 23 de novembro de 2001.

De maneira geral, o estado de conservação das duas vinícolas é precário, sobretudo no que se refere à situação das coberturas.

$\mathrm{Na}$ Vinícola Caruso Mac Donald, muitos locais de produção estão com os interiores expostos às 


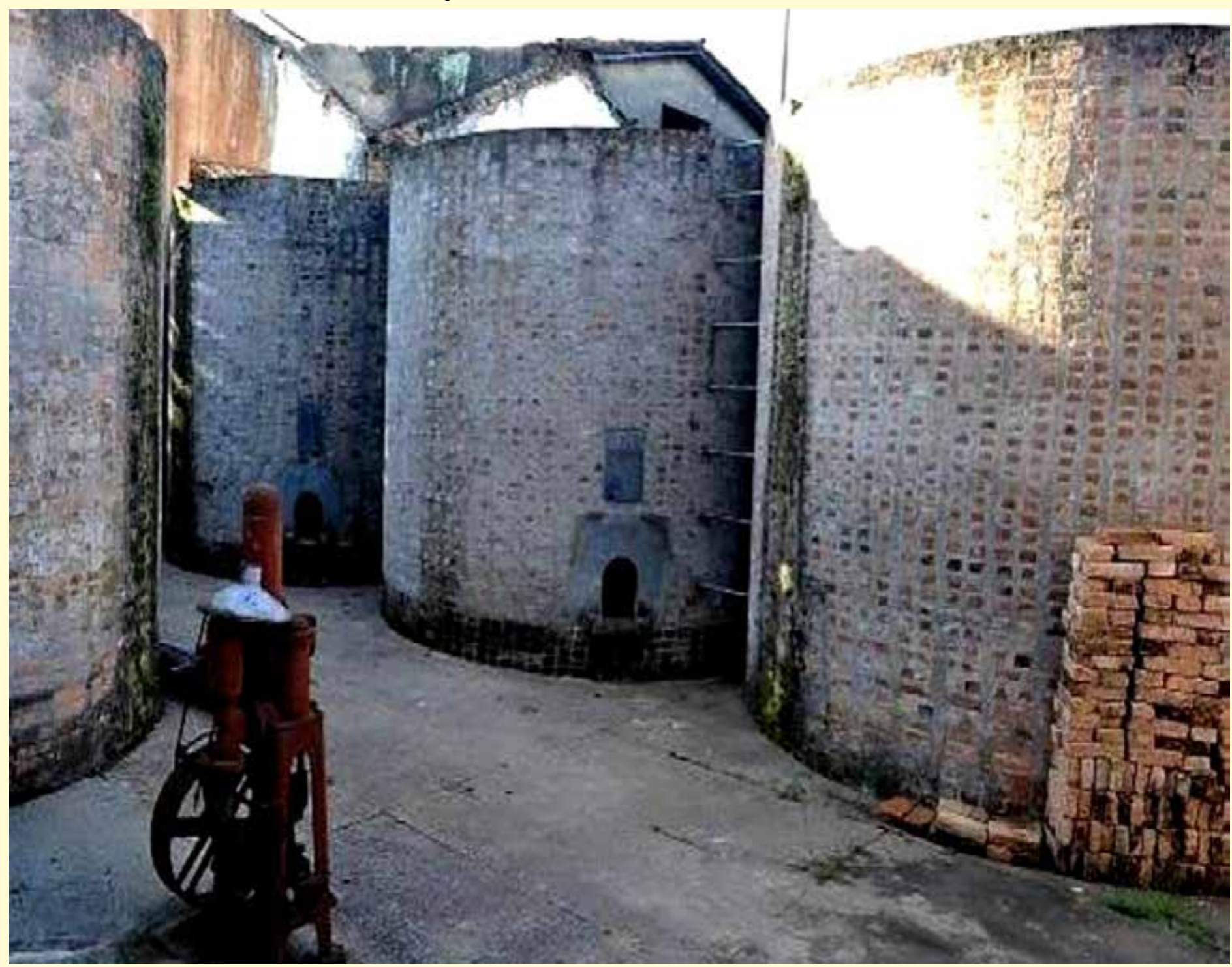

Fonte: Amaral (2014, p. 78).

intempéries, como pode ser visto na Imagem 8. Recebem manutenção somente os ambientes onde ainda existe atividade produtiva, sendo que os demais estão passando por um acentuado processo de degradação. As esquadrias não recebem manutenção adequada e muitas se encontram com a madeira deteriorada e com os vidros quebrados. Em função do estado de degradação, algumas esquadrias originais já foram removidas. A mesma situação de degradação acontece com as alvenarias, sendo possível observar em muitos locais o desprendimento do reboco e da pintura. Algumas paredes de alvenaria de tijolos apresentam estado de ruína. Observa-se, no edifício da Vinícola Caruso Mac Donald, grande incidência de manifestações patológicas nas fachadas de orientação sudeste e sudoeste, que são justamente as fachadas principais da edificação. É possível identificar em todas as fachadas danos em maior ou menor intensidade, possivelmente relacionados à ação da umidade, dando origem a desprendimento de tinta e ação de agentes biológicos. Observa-se que parte desses danos poderia ter sido evitada com pequenas ações preventivas de manutenção. Na Vinícola Cadorin, o estado de conservação dos antigos ambientes de produção de vinho é precário, também relacionado às coberturas, que necessitam de intervenção urgente. $\mathrm{O}$ madeiramento do telhado desses ambientes está comprometido pela incidência de umidade e pelo ataque de insetos xilófagos. As coberturas nesses recintos desativados apresentam risco de colapso, decorrente das ações de infiltrações que ocasionaram danos às alvenarias. Observa-se nas paredes externas e internas dessa vinícola a presença de umidade, desprendimento de reboco e da camada pictórica, além de patologias relacionadas à umidade, como a proliferação de microrganismos. As esquadrias localizadas no pavimento térreo da edificação primitiva se encontram em bom estado de conservação. Entretanto, muitas portas e janelas dos ambientes desativados da Vinícola Cadorin apresentam a madeira deteriorada e com as ferragens oxidadas. 
São várias as dificuldades encontradas para a preservação do patrimônio industrial, entre elas a grande quantidade de elementos a conservar e a falta de critérios específicos para esse tipo de bem. Além disso, os edifícios industriais geralmente passam por processos de ampliações e modificações, acompanhando a expansão dos negócios e a necessidade de novos maquinários e espaços para abrigar o aumento de produção. Com isso, muitas vezes se torna difícil compreender e desvendar as etapas construtivas que esses edifícios sofreram ao longo dos anos de atividades. Esse problema pode ser percebido durante as análises realizadas nos dois casos de estudo selecionados. As edificações estudadas possuem grandes dimensões e passaram por diversas fases construtivas de ampliações e anexos. A interpretação das alterações estruturais e morfológicas nem sempre foi tão evidente nos edifícios analisados, podendo-se constatar também a dificuldade em encontrar registros iconográficos e documentais. Pode-se concluir que as diferentes etapas construtivas das vinícolas resultaram em alterações nos perímetros das edificações e nas suas características arquitetônicas.

A Vinícola Caruso Mac Donald, desde o início, concentrou-se na produção de bebidas. Desse modo, o edifício foi construído essencialmente para abrigar a produção de vinhos, apresentando caráter industrial, que pode ser observado pelas tipologias das esquadrias e pela simplicidade formal do edifício. A edificação original dessa vinícola apresenta maior impacto na sua composição em relação aos edifícios construídos durantes as etapas de ampliação. Observou-se, também, que os edifícios que compreendem as quatro primeiras etapas possuem composição formal mais apurada, enquanto que os edifícios das demais são caracterizados pelo estilo simples. Com relação à Vinícola Cadorin, observou-se o grande impacto visual da edificação primitiva na composição do conjunto. Isso aconteceu devido ao fato do edifício abrigar, na época, a atividade produtiva no subsolo e a residência da família no pavimento térreo. Notadamente, o térreo se destaca pela ornamentação das fachadas e pelas esquadrias diferenciadas. As etapas de ampliação foram construídas essencialmente para abrigar ambientes produtivos que suprissem o aumento da fabricação de vinho. Desse modo, os edifícios mantiveram um estilo mais simples e sem muita ornamentação.

Considera-se como uma ameaça à preservação das antigas vinícolas o abandono das atividades tradicionais relativas à produção de vinho. A desativação da produção vinícola implicou o abandono dos edifícios. Levando em conta que o resgate dessa atividade pode se tornar inviável, julga-se relevante a utilização dessas construções para outros usos adequados, garantindo ao menos a conservação e a salvaguarda dessas edificações industriais. Acredita-se que as potencialidades enoturísticas estão ligadas ao seu patrimônio material e também imaterial, devendo-se levar em consideração o potencial de novos usos dessas edificações e os vínculos com a paisagem e a história da região. Antes de fazer qualquer intervenção em edifícios de valor histórico e cultural é primordial a realização da pesquisa histórica, identificando as características arquitetônicas e construtivas, e caracterizando o estado de conservação do edifício. Deste modo, a análise do estado de conservação das edificações antigas torna-se necessária, pois a degradação, o abandono e a falta de manutenção com frequência originam manifestações patológicas que podem colocar em risco a estabilidade das edificações. Apesar das dificuldades encontradas no reconhecimento de cronologias histórico-arquitetônicas em um patrimônio industrial, julga-se relevante esse tipo de análise por estabelecer parâmetros que podem nortear projetos de caráter preservacionista.

\section{Contribuição para o desenvolvimento turístico da região}

Os resultados das análises das duas vinícolas propiciaram conhecimentos acerca dos modos de construir, de morar e de trabalhar no início do século XX, na cidade de Urussanga. Esses conhecimentos podem fundamentar e auxiliar em intervenções que se façam necessárias nas vinícolas, por meio do diagnóstico e das características históricas e arquitetônicas das edificações que, segundo Valduga (2007), podem alavancar o potencial enoturístico da região. A preservação desses bens, legado dos imigrantes italianos, é essencial para a compreensão do passado e do presente, destacando a representatividade desses edifícios como parte do patrimônio histórico, turístico e cultural da região.

Deste modo, faz-se necessária a inserção das antigas vinícolas da imigração italiana no contexto cultural e turístico da região por meio de um itinerário cultural, incluindo essas edificações no roteiro turístico denominado 'Vales da Uva e do Vinho Goethe'. Já existe na região um roteiro composto por diversos pon- 
Dossiê

tos de visitação, entre eles as vinícolas, antigas serrarias, alambiques, igrejas e casas históricas da fase inicial da imigração italiana. Faz-se necessário, no entanto, sua melhor instrumentação, de modo a qualificá-lo e inseri-lo nos roteiros turísticos de Santa Catarina. O turismo cultural apresenta uma diversidade de interesses e modalidades, podendo a exploração do patrimônio arquitetônico ser referência para o conhecimento da história e da cultura das comunidades. As antigas vinícolas estudadas representam uma parte significativa dessa história, que necessita ser valorizada e preservada para que as novas gerações possam manter o elo com aqueles imigrantes que plantaram suas raízes e sua cultura. Roteiros turísticos qualificados, que incluam as vinícolas e suas paisagens, podem reforçar a identidade cultural, atraindo pessoas e recursos para garantir a preservação do patrimônio histórico da região.

\section{Referências}

AMARAL, T. Caracteriz̧ação do patrimônio industrial nas vinicolas Caruso Mac Donald e Cadorin em Urussanga-SC. 2014. Dissertação (Mestrado em Arquitetura e Urbanismo) - Universidade Federal de Santa Catarina, Florianópolis. 2014.

AMARAL, T.; BARTH, F. Vinícola Caruso Mac Donald: Caracterização e diagnóstico do patrimônio industrial em Urussanga-SC. Turismo e Sociedade, Curitiba, v. 7, n. 3, p. 467-494, jul. 2014.

BELOLLI, Mário et al. A história do carvão de Santa Catarina. Criciúma: Imprensa Oficial do Estado de Santa Catarina, 2002.

BRASIL. Constituição da República Federativa do Brasil. 35. ed. Brasília: Biblioteca Digital da Câmara de Deputados, 2012.

COSTA, Sérgio; COSTA, Márcia Neves Marques. Panorama da nossa gente. Urussanga: Costa Editorial e Gráfica, 1999-2000.

DANTAS, Fernando Antônio de Carvalho. Base jurídica para a proteção dos conhecimentos tradicionais. Revista CPC, v. 1, n. 2, p. 80-95, maio 2006.

FONTANA, Giovanni Luigi et al. Archeologia Industriale in Italia. Temi, progetti, esperienze. Brescia: Officine Grafiche Staged, 2005.

FUNDAÇÃO CATARINENSE DE CULTURA. Relatório técnico: conjunto de três edificações da Vinícola Cadorin Urussanga/SC. Florianópolis: Secretaria de Estado de Turismo, Cultura e Esporte, 2011.

MAESTRELLI, Sérgio Roberto. Do parreiral à taça. O vinho através da história. Urussanga: Epagri, 2011.

MARQUES, Mons. Agenor Neves. História de Urussanga. Urussanga: Do autor, 1990.

MATIOLA, V. et al. Urussanga: traços da história. Urussanga: Vanguarda Editorial, 2010.

MESTRES ARTÍFICES DE SANTA CATARINA: Cadernos de memória. Margareth C. A. Pimenta (Coord.). Brasilia: Iphan, 2012.

PIAZZA, Walter F. Italianos em Santa Catarina. Florianópolis: Lunardelli, 2001.

REBOLLAR, Paola May; VELLOSO, Carolina Quiumento; ERN, Rogério; VIEIRA, Hamilton Justino; SILVA, Aparecido Lima. Vales da wva Goethe. Urussanga: Ed. Progoethe; Gráfica Coan, 2007.

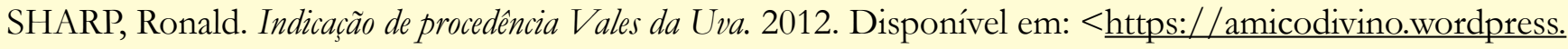
com/2012/07/12/vale-das-uva-goethe-indicacao-de-procedencia-brasileira > . Acesso em: 23 nov. 2015.

VALDUGA, Vander. O processo de desenvolvimento do enoturismo no Vale dos Vinhedos. 2007. Dissertação (Mestrado em Turismo) - Universidade de Caxias do Sul, Caxias do Sul. 2007.

VIEIRA, A. et al. A indicação geográfica como instrumento para o desenvolvimento de uma região: Caso de procedência de indicação do Vales da Uva Goethe (SC). Revista Propriedade Intelectual Direito Contemporâneo, Aracaju, v.3, n.5, p.403-425, fev. 2014. 